\title{
Nanoparticles Escaping RES and Endosome: Challenges for siRNA Delivery for Cancer Therapy
}

\author{
Shutao Guo and Leaf Huang \\ Division of Molecular Pharmaceutics, School of Pharmacy, University of North Carolina, Chapel Hill, NC 27599, USA \\ Correspondence should be addressed to Leaf Huang, leafh@email.unc.edu
}

Received 24 May 2011; Accepted 30 June 2011

Academic Editor: Xing J. Liang

Copyright (C) 2011 S. Guo and L. Huang. This is an open access article distributed under the Creative Commons Attribution License, which permits unrestricted use, distribution, and reproduction in any medium, provided the original work is properly cited.

\begin{abstract}
Small interfering RNAs (siRNAs) technology has emerged as a promising potential treatment for viral, genetic diseases and cancers. Despite the powerful therapeutic potential of siRNA, there are challenges for developing efficient and specific delivery systems for systemic administration. There are extracellular and intracellular barriers for nanoparticle-mediated delivery. First, nanoparticles are rapidly cleared from the circulation by the reticuloendothelial system (RES). Second, following their cellular uptake, nanoparticles are trapped in endosomes/lysosomes, where siRNA would be degraded by enzymes. In this review, we describe strategies for grafting a polyethylene glycol (PEG) brush to the nanoparticles for evading RES, such that they may effectively accumulate in the tumor by the enhanced permeability and retention (EPR) effect. PEG has to shed from the nanoparticles to allow close interaction with the tumor cells. Current strategies for facilitating endosome escape, such as ion pair formation, "proton sponge effect", destabilizing endosome membrane, and hydrophobic modification of the vector, are discussed.
\end{abstract}

\section{Introduction}

RNA interference was firstly discovered by Fire et al. in 1998 [1], and this technology has emerged as a powerful tool for analyzing gene function and inhibiting gene expression in cell culture and in animal models. Small interfering RNA (siRNA), resulting from the cleavage of longer double stranded RNA precursors by endonuclease dicer, could enter the RNA-induced silencing complex, where the complementary mRNA is degraded and as a result the expression of the corresponding protein is reduced $[2,3]$. However, systemic delivery of naked siRNA is limited by rapid blood clearance, RNA degradation, and poor cellular penetration due to the large molecular weight and negative charge of siRNA.

The success in the application of siRNA for cancer therapy is highly dependent on the development of vectors which are nontoxic and can selectively and efficiently deliver siRNA into the specific tissue in vivo $[4,5]$. Gene therapy vectors can be generally divided into two categories: viral vectors and nonviral vectors. Viral vectors are highly efficient, but the drawbacks of high cost, safety concerns and immunity significantly limit their application. To over the limitations of viral vectors, nonviral vectors have been widely developed as alter- natives. The majority of nonviral vectors are based on synthetic polymers and lipids. To date, these synthetic vectors are still relatively less efficient than viral vectors. It is a result of many barriers, extracellular as well as intracellular, encountered between the site of administration and the nucleus or cytoplasm of the target cells for DNA or siRNA delivery [5-8]. Extracellular barriers include condensing nucleic acid into stable complexes which would not be deassembled in the solution and blood, maintaining stability and circulation of nanoparticles in the blood stream, penetrating the tissue, and specific binding to the target cells of interest. Following internalization, gene delivery vectors are challenged by intracellular barriers, including endosome entrapment and nucleic acid unpacking from vectors. Among these barriers, escaping the reticuloendothelial system (RES) uptake and endosome will be focused in this review.

\section{Strategies for Nanoparticles Escaping RES Uptake}

The applications of siRNA in vitro and in vivo are hampered by their high molecular weight, negative charge, low stability, 
and rapid blood clearance [9-11]. Approaches to overcome these drawbacks have relied on nonviral siRNA carriers based on cationic polymers or lipids. Cationic vectors suffer from fast blood clearance by the RES. Nanoparticle size and surface charge are the two major properties strongly influencing the clearance $[12,13]$. Nanoparticle with the size of $100-$ $200 \mathrm{~nm}$ would readily accumulate and retain in the tumor interstitium because of the enhanced permeability and retention (EPR) effect [14-17], which is further facilitated by the lack of a draining lymphatic system in tumor tissues. The success of stealth nanoparticles for tumor therapy is highly dependent on reduced RES uptake and prolonged circulation time in the blood.

To prolong the circulation time, coating by polyethylene glycol (PEG), or PEGylation, is the most effective method to reduce protein adsorption in vivo and thereby helps to avoid the RES system [18-22]. Although there are successful attempts to develop alternative polymers to PEG, such as poloxamer [23, 24], polyvinyl alcohol $[25,26]$, poly(amino acid)s [27], and polysaccharide [28-31], PEG is still the most widely used material. PEG-lipid (such as PEG-DSPE) is usually inserted into liposomes to form a hydrated layer on the liposome surface. There are two kinds of conformation for PEG covering the surface of nanoparticles. For PEGDSPE-stabilized liposomes, PEG is ready to take mushroom conformation at low degree of PEGylation and will shift to brush conformation as the content of PEG-DSPE is increased to certain levels. The brush mode is the ideal configuration for protecting nanoparticles from serum absorption. However, due to the detergent-like property of PEG-lipid, it is difficult to form stable liposomes with high content of PEG-lipid. To tackle this problem, Li and Huang [32, 33] developed PEGylated liposome-polycation-DNA (LPD) nanoparticles by inserting PEG-DSPE after formation of LPD nanoparticles. Negative and nanosized cores were formed by condensing DNA with protamine, which then bind cationic lipids to form DNA/protamine-encapsulated liposomes. The DNA/protamine cores played an important role to stabilize liposomes by electrostatic interaction. Therefore, LPD nanoparticles were still stable, even if 10.6\% (by molar) of PEG-lipid was incorporated into the LPD nanoparticles $[32,33]$. Stealth LPD nanoparticles were characterized by lower liver uptake through evasion of RES uptake and efficient delivery of siRNA to tumors [34, 35]. After 4 hours of i.v. injection, RES uptake of LPD nanoparticles was as low as $5-15 \%$ of the injected dose, and $30 \%$ of the dose accumulated in the tumor. It was hypothesized that the brushed PEG shed overtime, resulting in reducing the PEG content in the nanoparticles and further blood clearance [33, 36-38]. Pharmacokinetics (PK) data showing a rapid distribution phase and not much prolonged circulation time of the injected particles is consistent with the hypothesis. PEG shedding, which is not well understood and requires further study, is important for endosome escape and cargo discharge after the nanoparticle enters into the cell by endocytosis. This aspect will be discussed in Section 3.

To overcome the PEG dilemma, several strategies are designed. The first strategy is to modify the nanoparticles with tumor-specific ligand to enhance intracellular uptake.
Among the ligands, iron-saturated transferrin (Tf) has been widely investigated to target tumor cells overexpressing Tfreceptors [39-43]. Ogris et al. [40] demonstrated that Tfbearing PEG-polyethyleneimine (PEI) could selectively deliver plasmid into tumor, leading to 100 -fold higher gene expression in tumor cells than that of other tissues. Bartlett et al. [10] prepared siRNA-containing, Tf-targeted nanoparticles. Although Tf could not enhance the accumulation of nanoparticles in the tumor in mice, it facilitated cell uptake of nanoparticles, thereby improved gene knockdown efficiency. Very recently, they performed the first gene inhibition experiment by administration of Tf-targeted, siRNA-containing cyclodextrin containing polycation (CDP) nanoparticles in humans [42] and showed that siRNA successfully silenced the target gene in both mRNA and protein levels. In addition, several other ligands, such as RGD [44, 45], CNGRC [46], anisamide $[35,45,47]$, and folate $[48,49]$, have also been applied to target specific tumor delivery in vivo.

Ligand-mediated nanoparticles are usually internalized into tumor cells by receptor-mediated endocytosis and finally taken up into endosomal/lysosomal vesicles. Therefore, the second strategy is to incorporate sheddable PEG to facilitate drug escape from endosomal/lysosomal vesicles. Exploiting the microenvironment of tumor and acidic nature of endosome, PEG-lipids and polyplexes with $\mathrm{pH}$-sensitive degradable spacers are used to prepare PEG sheddable liposomes and cationic polymer vectors. Usually, $\mathrm{pH}$-sensitive degradable bonds are orthoester [50,51], hydrazone [52, 53], vinyl ethers [54], or acetals [55], and this has been reviewed elsewhere [56]. Enzyme cleavable PEG has also been developed $[57,58]$. In addition to use sheddable PEG, we will discuss other methods to facilitate disruption of the endosomal membrane in the next section.

In addition to the PEG dilemma, another problem of PEGylation, that is, accelerated blood clearance (ABC), has been reported [59]. Although PEGylation could significantly prolong the circulation time of nanoparticles in the blood, repeated i.v. injections of the PEGylated nanoparticles resulted in the lost of the long-circulating characteristics [59-61]. The mechanism of ABC developed by Ishida et al. is that first injected dose of PEGylated liposomes activates the splenic synthesis of anti-PEG IgM, resulting in the opsonization of the second dose of PEGylated liposomes and uptake by the liver Kupffer cells [62-64].

To overcome the ABC problem, alternative hydrophilic polymers (such as poly(N-vinyl-2-pyrrolidone) (PVP) and poly(hydroxyethyl-l-asparagine) (PHEA)) $[65,66]$ and cleavable PEG-lipid derivatives [67] are used. PVP-coated nanoparticles showed improved blood circulation and no ABC phenomenon [65]. For in vivo siRNA delivery, Kiwada group [68] demonstrated that conventional PEG-coated siRNAlipoplex (PSCL) also caused anti-PEG IgM production, which is lower than that of PEG-coated naked cationic liposomes (PCL). A similar PEGylated lipid nanocarrier termed PEGylated wrapsome (PEG-WS) was further developed for siRNA delivery $[69,70]$. Anti-PEG IgM production of the new PEG-WS formulation is less than that of PSCL and significantly dependant on the sequence of siRNA [70]. It shows that anti-PEG IgM production induced by potent immune 
stimulatory siRNA is much higher, and 2'-O-methyl (2'$\mathrm{OMe}$ ) uridine modification can significantly reduce antiPEG IgM production by inhibiting cytokine induction.

\section{Strategies for Promoting Nanoparticles Escape from Endosome}

Having solved the problems with RES uptake, another challenge for siRNA delivery is to have the cargo escape from endosomes to reach cytoplasm. Here several strategies designed to enhance endosomal escape are described (Table 1).

3.1. Ion-Pair Formation. The mechanism whereby cationic lipids destabilize endosome membrane to facilitate the endosomal escape of nucleic acid such as plasmid DNA or siRNA is originally proposed by $\mathrm{Xu}$ and Szoka [105]. Cationic lipids form ion pairs with anionic lipids within endosome membrane to destabilize the endosome membrane. Because the cross-sectional area of the combined headgroup in ion pair is less than that of the sum of individual headgroup areas in isolation, a "cylindrical" shape of individual charged lipids is transformed to a "cone" shape of ion pair which further promote the formation of the inverted hexagonal $\left(\mathrm{H}_{\mathrm{II}}\right)$ phase as proposed by Cullis et al. [128, 129].

The exposure of the positive charge in liposomes to endosomal membranes is a prerequisite for electrostatic interaction between cationic lipids and anionic lipids. PEGylation of liposomes for systemic drug delivery therefore inhibits the formation of ion pairs. As mentioned in Section 2, the shedding character of LPD nanoparticles is helpful to overcome the PEG dilemma [32-35]. After PEG comes off the LPD nanoparticles, cationic lipids are exposed to anionic lipids. In this novel formulation, the brushed but sheddable PEG not only grants LPD nanoparticles evasion of the RES for the initial period of time such that LPD nanoparticles can penetrate into the tumor by EPR effect but also facilitates the endosomal escape of the cargo siRNA. Due to successful RES evasion and endosomal escape, LPD nanoparticle is a very promising carrier for systemic delivery of siRNA.

Obata et al. [108] synthesized zwitterionic lipids with amino acid-modified head group. The fusogenic potential of these liposomes with endosome-mimicking anionic membrane is $\mathrm{pH}$-responsive, and it increases as $\mathrm{pH}$ decreases. The zeta potential of these liposomes in physiological conditions is negative and switches to positive as $\mathrm{pH}$ declines, which means that these lipoplexes may have prolonged circulation time in the blood. The properties of these liposomes provided great promise for drug delivery in vivo but no such report has been seen yet.

Heyes et al. [130] synthesized 1,2-dilinoleyloxy-3-dimethylaminopropane (DLinDMA) lipid with two double bonds per alkyl chain, which has strong fusogenicity and high gene transfection efficiency. Recently, Semple et al. [131] developed DLinDMA derivatives by optimizing the headgroup and linker moiety to formulate stable nucleic acidlipid particles (SNALPs). They introduced an acid degradable ketalized linker. SNALP formulation containing DLin-KC2DMA lipid presented excellent in vivo silencing activity in liver in rodents and nonhuman primates. This novel for- mulation could evade RES uptake and circulate in the blood for longer time due to its low $\mathrm{pKa}$ under neutral $\mathrm{pH}$, because the amine head groups remain unprotonated and the zeta potential of nanoparticles was nearly neural or negative at $\mathrm{pH}$ 7.4. After the nanoparticles were internalized into intracellular endosomes, the amine groups became protonated to form cationic lipids, which was necessary to escape endosome by ion-pair mechanism. As known, it is difficult for liposome formulations to avoid drug leakage in the blood on one hand and achieve rapid drug release in target tissues on the other [132-137]. In this novel SNALP formulation, the hydrolysis of ketal bond might increase the content of neutral lipid in liposomes, which likely triggers siRNA release due to reorganization of the lipid domains $[138,139]$ and is key for its excellent performance at in vivo siRNA delivery. Therefore, this formulation may be advantageous to release cargo efficiently from both endosome and liposomes.

3.2. "Proton Sponge Effect". Successful escape of siRNA carriers from endosome and release of the payload into cytoplasm is necessary to improve the efficiency of gene silencing. Due to the acid nature of endosomal/lysosomal vesicles, $\mathrm{pH}$-buffering agents are widely exploited to promote cargo release. Under acidic condition, various macromolecules with low pKa amine group have been shown to exhibit "proton sponge effect", such as PEI and its derivates [74, 94, 140, 141]. When the complexes formed by these compounds and nucleic acid are internalized into the cell, these compounds are capable of buffering the endosomal vesicle, leading to endosomal swelling and lysis, thus releasing the nucleic acids into the cytoplasm.

Charge-reversal copolymers could shift their charge nature between positive and negative in a $\mathrm{pH}$-dependent fashion $[76-79,142]$. Charge conversion can occur in acidic intracellular organelles such as endosome or lysosome $(\mathrm{pH}=$ $5 \sim 6$ ), and then these copolymers facilitate the endosomal escape of nucleic acids by enhancing the capacity of "proton sponge". Pittella et al. [79] synthesized a hybrid nanocarrier system composed of calcium phosphate $(\mathrm{CaP})$, a block copolymer PEG, and a charge-conversional polymer (CCP) to deliver siRNA. Confocal laser scanning microscopic observation confirmed that CCP was helpful for endosomal escape of siRNA with the nanoparticles. This hybrid nanocarrier system achieved significant knockdown of vascular endothelial growth factor (VEGF) in PanC-1 cells with low cytotoxicity. Guo et al. prepared charge-reversal functionalized gold nanoparticles (CRFGNs) with cis-aconitic anhydridefunctionalized poly(allylamine) (PAH-Cit) [75]. The charge reversion of PAH-Cit was confirmed by polyacrylamide gel electrophoresis and confocal laser scanning microscopy. In vitro quantification of lamin $\mathrm{A} / \mathrm{C}$ protein expression by western blot indicated that the knockdown efficiency of siRNA delivered by CRFGN was dose-dependent in Hela cell line. At 10:1 Au: siRNA ratio, siRNA delivered by CRFGN achieved the highest $(80.0 \%)$ knockdown efficiency, which is better than Lipofectamine 2000 which inhibited about $66.0 \%$. CRFGN achieved similar results in DNA transfection experiments. 


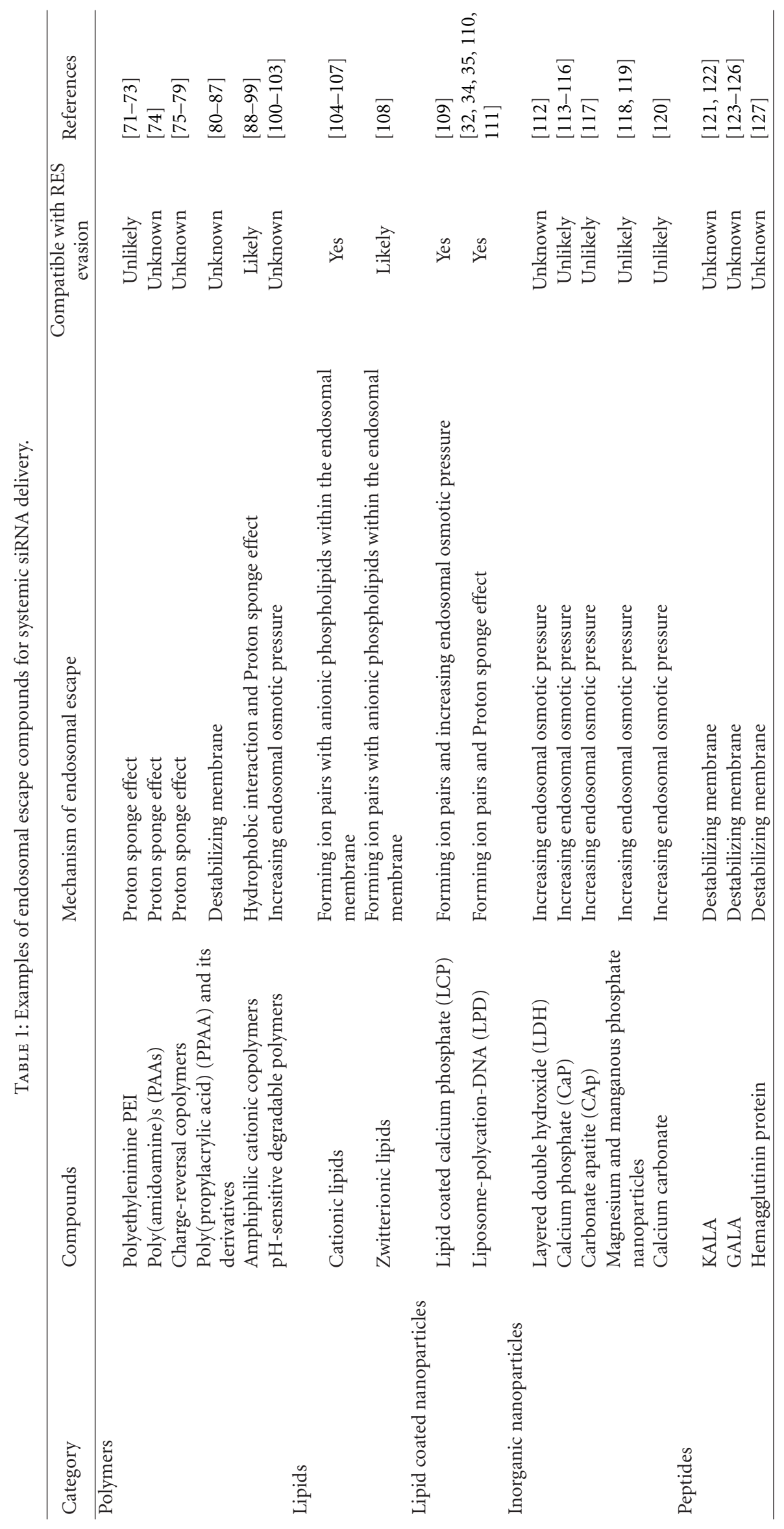


In fact, layered double hydroxide (LDH) [112], calcium phosphate $[116,124]$, and some other inorganic nanoparticles [118] also belong to materials which are able to deplete protons in acid environment. Because these nanoparticles could be degraded in acidic buffer, they are also able to release cargo from endosomal vesicles. For example, siRNAloaded LDH nanoparticles [112] were dissolved due to the low $\mathrm{pH}$ in the endosome, which facilitated cargo escape from endosomes into the cytoplasm and significant downregulation of protein expression in HEK293T cells. Carbonate apatite nanoparticles [117] were developed to facilitate siRNA escape from the endosomes. It was remarkable that carbonate apatite nanoparticles could efficiently silence reporter genes at a low dose and were more efficient than Lipofectamine. Calcium phosphate has been widely used in biomaterials due to excellent biocompatibility. In vitro gene transfection efficiency of calcium phosphate nanoparticles with hydroxyapatite phase structure was found to be higher than that of the commercial transfecting reagent Polyfect [116]. Nevertheless, these particles are not stable and readily form large aggregates; therefore their in vivo applications are limited. To synthesize stable siRNA-loaded calcium phosphate, Kataoka et al. [113-115] utilized PEG-polycarboxylate block copolymer (such as PEG-b-poly(aspartic acid) and PEG-b-poly(methacrylic acid)) to achieve stable and sizecontrolled $\mathrm{CaP}$ nanoparticles, which showed good stability in serum and significant gene knockdown in vitro. Incorporation of PEG-SS-siRNA instead of PEG-polycarboxylate for stabilization achieved high PEG density in CaP nanoparticles, which could be potentially useful for the systemic delivery of siRNA. The PEG-stabilized CaP nanoparticles were observed to escape from endosome/lysosome exhibited RNAi efficacy for in vitro gene silencing. To improve the endosomal escape of CaP nanoparticles, a diblock copolymer composed of PEG and a charge-reversal polymer was incorporated [79] and resulting hybrid nanoparticles showed significant VEGF knockdown in PanC-1 cells because of the rapid endosomal escape. However, there is no in vivo study of PEG-stabilized CaP nanoparticles for siRNA delivery.

Recently, Li et al. [109] prepared siRNA-encapsulated calcium phosphate by reverse water-in-oil microemulsion technique and then coated calcium phosphate nanoparticles with lipid to obtain a novel siRNA formulation of lipidcoated calcium phosphate (LCP) nanoparticle for siRNA systemic delivery. As mentioned before, calcium phosphate is acid-sensitive, and its degradation in endosome/lysosome increases osmotic pressure of endosome, leading to release of siRNA into the cytoplasm. In addition, lipid component is well known to be helpful for nanoparticles uptake and cargo release from endosome. Antiluciferse (luc) siRNA-loaded LCP nanoparticles showed significant gene silencing of luciferase both in vitro and in vivo with negligible immunotoxicity. The in vivo results suggested that LCP nanoparticles offer significant promise for siRNA delivery in clinical trails.

3.3. Membrane-Destabilizing Macromolecules. To date, there is no kind of synthetic vector which has comparable efficiency as viral vectors. Hemagglutinin protein, which is $\mathrm{pH}$ sensitive and membrane-destabilizing, helps viral vectors to disrupt the endosome efficiently and enter the cytoplasm [127]. The escape mechanism of hemagglutinin and other fusion proteins is that they shift from an ionized and hydrophilic conformation to a hydrophobic and membrane-active conformation as the environment changes from neutral to acidic, resulting in destabilization of the endosomal membrane and its leakage subsequently. Therefore, incorporation of membrane-destabilizing peptides is another effective strategy to utilize the low $\mathrm{pH}$ environment of endosomes/ lysosomes.

To mimic the function of viral hemagglutinin protein, many peptides $[123,143-145]$ and polymers $[80,146-149]$ with similar properties were synthesized to enhance gene and siRNA delivery. Among the synthetic peptides, the GALA peptide (WEAALAEALAEALAEHLAEALAEALEALAA)

[123] was the most studied. Harashima group has developed a kind of multifunctional envelope type nanodevice (MEND) combining PEGylation, targeting ligand, and GALA. It was demonstrated that GALA facilitated endosomal release of siRNA, resulting in efficient knockdown [124-126]. In an in vivo gene silencing study, different MENDs with antiluciferase siRNA were directly injected into tumors of T1080-luctumor-bearing mice, and compared to unmodified MEND, GALA-modified MEND exhibited greater gene silencing in tumor tissues. On the other hand, poly(propylacrylic acid) (PPAA) was the most efficient and most studied membrane-destabilizing synthetic polymers, and its membranedestabilizing capacity could be enhanced by copolymerization with hydrophobic monomers [80-84]. PPAA was demonstrated to enhance the transfection efficiency of cationic lipid/pDNA complexes both in vitro and in vivo $[81,85]$. PPAA is negatively charged at physiological condition and therefore cannot condense siRNA directly. Stayton et al. synthesized a kind of diblock polymer composed of poly(2-(dimethylamino)ethyl methacrylate) (PDMAEMA) to condense siRNA and a second endosomalreleasing block composed of DMAEMA and propylacrylic acid (PAA) in roughly equimolar ratios, together with butyl methacylate (BMA). These carriers became sharply lytic at endosomal $\mathrm{pH}$ range. In HeLa cells, a copolymer with the most hydrophobic second block (highest BMA content) exhibited the best knockdown effect [86]. When the length of endosomolytic block and its hydrophobic content were increased, this type of copolymer could self-assemble into spherical micelle. The cationic micelle presented much higher knockdown efficiency at low siRNA dose as compared to nonmicelle formulations. These results also indicated that hydrophobic property should contribute significantly to enhancing siRNA knockdown efficiency [87]. Similarly, Lin et al. [150] synthesized a comb-like polymers constructed by a copolymer of $\mathrm{pH}$-sensitive EAA monomers and hydrophobic BMA or hexyl methacrylate (HMA) as the backbone and a second copolymer of hydrophobic HMA and cationic trimethylaminoethylmethacrylate (TMAEMA) at a 50/50 molar feed ratio as grafts. The grafts were linked to the backbone by the acid-labile hydrazone bond. These comb-like polymers could deliver anti-GAPDH siRNA molecules and successfully silenced GAPDH expression at both the mRNA and protein levels in MCF-7 cells. 
3.4. Hydrophobic Modifications of Cationic Polymers. For gene delivery, it has been widely reported that hydrophobic modification of cationic polymers could improve the interaction between vectors, resulting in more efficient escape by lysis of the endosomes and therefore higher gene transfection efficiency [151-155]. Recently, hydrophobic-modified or amphiphilic cationic copolymers are also used as vectors to deliver siRNA [89-91, 94-98, 156]. Kim et al. $[88,89]$ synthesized water soluble lipopolymer (WSLP) by conjugating cholesterol with short PEI $(1.8 \mathrm{kDa})$ or oligoarginine. WSLP/siRNA complexes showed successful VEGF knockdown in vitro and significant repression of tumor growth in vivo via intratumoral injection. Similarly, branched PEI (25 kDa) derivatives, such as PEI modified by oleic acid and stearic acid [90], tyrosine [92] or PEI grafted with hydrophobic poly ( $\gamma$-benzyl L-glutamate) segment [93], and low molecular weight PEI ( $800 \mathrm{Da})$ modified by Michael addition with alkyl acrylates [91], could condense siRNA into more stable nanoparticles and present better siRNA silencing effect than PEI and were comparable to some of the commercially available transfection agents. These branched PEI derivatives also have low cytotoxicity.

Mao et al. [96, 97] reported self-assembled nanoparticles of monomethoxy poly(ethylene glycol)-block-poly(caprolactone)-block poly(2-aminoethyl ethylene phosphate) (PPEEA) (mPEG-b-PCL-b-PPEEA). Micellar nanoparticles have several advantages over hydrophilic cationic coplolymers. For example, micellar nanoparticles could load nucleic acids and hydrophobic anticancer drugs simultaneously. Anticeramidase siRNA-loaded nanoparticles showed significant gene knockdown activities toward the endogenous acid ceramidase gene in vitro and significant inhibition of tumor growth in a BT474 xenograft murine model via tail vein injection. Evaluation of immunotoxicity indicated that this delivery system did not induce immune response. Xiong et al. [95] synthesized a type of biodegradable amphiphilic poly(ethylene oxide)-block-polycaprolactone (PEO-bPCL) with grafted polyamines for siRNA delivery. These polyamine-grafted PEO-b-PCL micelles could efficiently deliver MDR-1-targeted siRNA to silence P-gp expression in vitro and showed effective endosomal escape after cellular uptake.

Additionally, amphiphilic copolymers have been explored in an effort to deliver nucleic acids and hydrophobic drug paclitaxel into cancer cells [98, 99]. Zhu et al. [98] synthesized PDMAEMA-PCL-PDMAEMA triblock copolymers by RAFT polymerization method. Polymeric micelles/antiGFP siRNA complexes showed more efficient knockdown than PDMAEMA (20 kDa) and PEI (25 kDa) in MDA-MB435-GFP cells, and codelivery of VEGF siRNA and paclitaxel with polymeric micelles/siRNA complexes achieved synergistic effects in inhibiting tumor cell growth in vitro.

3.5. pH-Sensitive Degradable Vectors. In addition to the ability to escape from endosomes, the ideal siRNA delivery vectors should be able to release siRNA into the cytoplasm. Among the $\mathrm{pH}$-sensitive bonds, acetal bond has been widely used to construct intelligent macromolecules or lipid vectors for drug delivery [100-103, 131, 157], due to its fast degrada- tion in endosomal environment. Materials containing acetal bonds are supposed to be degraded in endosomes which precedes the release of their cargo. Hydrolysis of acetal bond will consume hydrogen, which also helps cargo escape from endosome by increasing endosomal osmotic pressure.

Shim and Kwon [101, 157, 158] developed acid-degradable ketalized branched PEI and linear PEI. These derived PEIs showed significant gene transfection efficiency and siRNA knockdown effect when compositions of the polymers were optimized. Some of them could selectively release siRNA from the endosome into cytoplasm with reduced cytotoxicity. To achieve efficient dissociate of carrier with nucleic acids, they synthesized PEG-conjugated aciddegradable poly(ketalized serine) [100] and degradable polyspermine by Michael addition [103].

\section{Conclusions}

To date, lipid and polymeric nanoparticles have already been widely used for siRNA delivery. For nanoparticles to efficiently deliver siRNA into target tissue and silence target genes, they must overcome two major hurdles: RES uptake and endosome entrapment. Long-circulation property is the prerequisite for nanoparticles to carry most of the siRNA cargo into the target site of interest. Circulation half-life in the blood can be improved by PEGylation or coating a neural and anionic shell. Facilitating endosomal escape is another important strategy in improving drug bioavailability. Incorporation of sheddable-PEG into nanoparticles can help solve the PEG dilemma and promote nanoparticles to escape from endosomes. Tested strategies exploiting ion pair formation, "proton sponge effect", or adding endosome destabilizing agents are effective in improving endosome escape. However, most of these endosome escape mechanisms are not compatible with RES evasion such that only local administration of the dosage form can be attempted. Some newly developed nanoparticles (LPD and LCP), which are able to escape from the endosome, deassemble, and release siRNA simultaneously, certainly represent a class of improved vectors for siRNA delivery in vivo.

\section{Abbreviations}

siRNA: Small interfering RNA

RES: Reticuloendothelial system

PEG: Polyethylene glycol

EPR: Enhanced permeability and retention

LPD: Liposome-polycation-DNA

PK: Pharmacokinetics

PAA: Poly(amidoamine)

PEI: Polyethyleneimine

PPAA: Poly(propylacrylic acid)

LCP: Lipid coated calcium phosphate (LCP)

LDH: Layered double hydroxide

CaP: Calcium phosphate

Cap: Carbonate apatite 


\begin{tabular}{|c|c|}
\hline SNALP: & $\begin{array}{l}\text { Stable nucleic acid-lipid } \\
\text { particles }\end{array}$ \\
\hline DLinDMA: & $\begin{array}{l}\text { 1,2-dilinoleyloxy-3- } \\
\text { dimethylaminopropane }\end{array}$ \\
\hline CCP: & Charge-conversional polymer \\
\hline VEGF: & $\begin{array}{l}\text { Vascular endothelial growth } \\
\text { factor }\end{array}$ \\
\hline PAH-Cit: & $\begin{array}{l}\text { cis-aconitic } \\
\text { anhydride-functionalized } \\
\text { poly(allylamine) }\end{array}$ \\
\hline MEND: & $\begin{array}{l}\text { Multifunctional envelope type } \\
\text { nanodevice }\end{array}$ \\
\hline PDMAEMA: & $\begin{array}{l}\text { poly }(2 \text {-(dimethylamino)ethyl } \\
\text { methacrylate) }\end{array}$ \\
\hline BMA: & Butyl methacylate \\
\hline HMA: & hexyl methacrylate \\
\hline TMAEMA: & $\begin{array}{l}\text { Trimethylaminoethyl- } \\
\text { methacrylate }\end{array}$ \\
\hline $\begin{array}{l}\text { WSLP: } \\
\text { mPEG-b-PCL-b-PPEEA: }\end{array}$ & $\begin{array}{l}\text { Water soluble lipopolymer } \\
\text { monomethoxy poly(ethylene } \\
\text { glycol)-block- } \\
\text { poly(caprolactone)-block } \\
\text { poly(2-aminoethyl ethylene } \\
\text { phosphate) }\end{array}$ \\
\hline PEO-b-PCL: & $\begin{array}{l}\text { poly(ethylene } \\
\text { oxide)-block-polycaprolactone }\end{array}$ \\
\hline
\end{tabular}

\section{Acknowledgments}

The work in authors' lab has been supported by NIH Grants CA149363, CA129421, and CA129835. Editorial assistance by Yadi Tan is appreciated.

\section{References}

[1] A. Fire, S. Xu, M. K. Montgomery, S. A. Kostas, S. E. Driver, and C. C. Mello, "Potent and specific genetic interference by double-stranded RNA in caenorhabditis elegans," Nature, vol. 391, no. 6669, pp. 806-811, 1998.

[2] H. Zhang, F. A. Kolb, L. Jaskiewicz, E. Westhof, and W. Filipowicz, "Single processing center models for human Dicer and bacterial RNase III," Cell, vol. 118, no. 1, pp. 5768, 2004

[3] C. Matranga, Y. Tomari, C. Shin, D. P. Bartel, and P. D. Zamore, "Passenger-strand cleavage facilitates assembly of siRNA into Ago2-containing RNAi enzyme complexes," Cell, vol. 123, no. 4, pp. 607-620, 2005.

[4] M. Nishikawa and L. Huang, "Nonviral vectors in the new millennium: delivery barriers in gene transfer," Human Gene Therapy, vol. 12, no. 8, pp. 861-870, 2001.

[5] D. W. Pack, A. S. Hoffman, S. Pun, and P. S. Stayton, "Design and development of polymers for gene delivery," Nature Reviews Drug Discovery, vol. 4, no. 7, pp. 581-593, 2005.

[6] K. A. Whitehead, R. Langer, and D. G. Anderson, "Knocking down barriers: advances in siRNA delivery," Nature Reviews Drug Discovery, vol. 8, no. 2, pp. 129-138, 2009.

[7] Y. Wang, Z. Li, Y. Han, L. H. Liang, and A. Ji, "Nanoparticlebased delivery system for application of siRNA in vivo," Current Drug Metabolism, vol. 11, no. 2, pp. 182-196, 2010.
[8] C. M. Wiethoff and C. R. Middaugh, "Barriers to nonviral gene delivery," Journal of Pharmaceutical Sciences, vol. 92, no. 2, pp. 203-217, 2003.

[9] J. Soutschek, A. Akinc, B. Bramlage et al., "Therapeutic silencing of an endogenous gene by systemic administration of modified siRNAs," Nature, vol. 432, no. 7014, pp. 173-178, 2004.

[10] D. W. Bartlett, H. Su, I. J. Hildebrandt, W. A. Weber, and M. E. Davis, "Impact of tumor-specific targeting on the biodistribution and efficacy of siRNA nanoparticles measured by multimodality in vivo imaging," Proceedings of the National Academy of Sciences of the United States of America, vol. 104, no. 39, pp. 15549-15554, 2007.

[11] F. Sams-Dodd, "Target-based drug discovery: is something wrong?” Drug Discovery Today, vol. 10, no. 2, pp. 139-147, 2005.

[12] S. K. Hobbs, W. L. Monsky, F. Yuan et al., "Regulation of transport pathways in tumor vessels: role of tumor type and microenvironment," Proceedings of the National Academy of Sciences of the United States of America, vol. 95, no. 8, pp. 4607-4612, 1998.

[13] T. L. Andresen, S. S. Jensen, and K. Jørgensen, "Advanced strategies in liposomal cancer therapy: problems and prospects of active and tumor specific drug release," Progress in Lipid Research, vol. 44, no. 1, pp. 68-97, 2005.

[14] Y. Matsumura and H. Maeda, "A new concept for macromolecular therapeutics in cancer chemotherapy: mechanism of tumoritropic accumulation of proteins and the antitumor agent smancs," Cancer Research, vol. 46, no. 12, pp. 63876392, 1986.

[15] H. Maeda, L. W. Seymour, and Y. Miyamoto, "Conjugates of anticancer agents and polymers: advantages of macromolecular therapeutics in vivo," Bioconjugate Chemistry, vol. 3, no. 5, pp. 351-362, 1992.

[16] H. Maeda, J. Wu, T. Sawa, Y. Matsumura, and K. Hori, "Tumor vascular permeability and the EPR effect in macromolecular therapeutics: a review," Journal of Controlled Release, vol. 65, no. 1-2, pp. 271-284, 2000.

[17] K. Maruyama, "Intracellular targeting delivery of liposomal drugs to solid tumors based on EPR effects," Advanced Drug Delivery Reviews, vol. 63, no. 3, pp. 161-169, 2011.

[18] A. L. Klibanov, K. Maruyama, V. P. Torchilin, and L. Huang, "Amphipathic polyethyleneglycols effectively prolong the circulation time of liposomes," FEBS Letters, vol. 268, no. 1, pp. 235-237, 1990.

[19] T. M. Allen and A. Chonn, "Large unilamellar liposomes with low uptake into the reticuloendothelial system," FEBS Letters, vol. 223, no. 1, pp. 42-46, 1987.

[20] T. M. Allen, C. Hansen, and J. Rutledge, "Liposomes with prolonged circulation times: factors affecting uptake by reticuloendothelial and other tissues," Biochimica et Biophysica Acta, vol. 981, no. 1, pp. 27-35, 1989.

[21] T. M. Allen, C. Hansen, F. Martin, C. Redemann, and A. F. Yau-Young, "Liposomes containing synthetic lipid derivatives of poly(ethylene glycol) show prolonged circulation half-lives in vivo," Biochimica et Biophysica Acta, vol. 1066, no. 1, pp. 29-36, 1991.

[22] A. L. Klibanov, K. Maruyama, A. M. Beckerleg, V. P. Torchilin, and L. Huang, "Activity of amphipathic poly(ethylene glycol) 5000 to prolong the circulation time of liposomes depends on the liposome size and is unfavorable for immunoliposome binding to target," Biochimica et Biophysica Acta, vol. 1062, no. 2, pp. 142-148, 1991. 
[23] R. H. Müller, S. Maaßen, H. Weyhers, and W. Mehnert, "Phagocytic uptake and cytotoxicity of solid lipid nanoparticles (SLN) sterically stabilized with poloxamine 908 and poloxamer 407," Journal of Drug Targeting, vol. 4, no. 3, pp. 161-170, 1996.

[24] M. Morille, T. Montier, P. Legras et al., "Long-circulating DNA lipid nanocapsules as new vector for passive tumor targeting," Biomaterials, vol. 31, no. 2, pp. 321-329, 2010.

[25] H. Takeuchi, H. Kojima, H. Yamamoto, and Y. Kawashima, "Polymer coating of liposomes with a modified polyvinyl alcohol and their systemic circulation and RES uptake in rats," Journal of Controlled Release, vol. 68, no. 2, pp. 195-205, 2000.

[26] H. Takeuchi, H. Kojima, T. Toyoda, H. Yamamoto, T. Hino, and Y. Kawashima, "Prolonged circulation time of doxorubicin-loaded liposomes coated with a modified polyvinyl alcohol after intravenous injection in rats," European Journal of Pharmaceutics and Biopharmaceutics, vol. 48, no. 2, pp. 123-129, 1999.

[27] J. M. Metselaar, P. Bruin, L. W. T. de Boer et al., "A novel family of L-amino acid-based biodegradable polymer-lipid conjugates for the development of long-circulating liposomes with effective drug-targeting capacity," Bioconjugate Chemistry, vol. 14, no. 6, pp. 1156-1164, 2003.

[28] V. Sihorkar and S. P. Vyas, "Potential of polysaccharide anchored liposomes in drug delivery, targeting and immunization," Journal of Pharmacy and Pharmaceutical Sciences, vol. 4, no. 2, pp. 138-158, 2001.

[29] D. Peer, J. E. Park, Y. Morishita, C. V. Carman, and M. Shimaoka, "Systemic leukocyte-directed siRNA delivery revealing cyclin D1 as an anti-inflammatory target," Science, vol. 319, no. 5863, pp. 627-630, 2008.

[30] Z. S. Haidar, R. C. Hamdy, and M. Tabrizian, "Protein release kinetics for core-shell hybrid nanoparticles based on the layer-by-layer assembly of alginate and chitosan on liposomes," Biomaterials, vol. 29, no. 9, pp. 1207-1215, 2008.

[31] M. Mobed and T. M. S. Chang, "Comparison of polymerically stabilized PEG-grafted liposomes and physically adsorbed carboxymethylchitin and carboxymethyl/glycolchitin liposomes for biological applications," Biomaterials, vol. 19, no. 13, pp. 1167-1177, 1998.

[32] S. D. Li and L. Huang, "Nanoparticles evading the reticuloendothelial system: role of the supported bilayer," Biochimica et Biophysica Acta, vol. 1788, no. 10, pp. 2259-2266, 2009.

[33] S. D. Li and L. Huang, "Stealth nanoparticles: high density but sheddable PEG is a key for tumor targeting," Journal of Controlled Release, vol. 145, no. 3, pp. 178-181, 2010.

[34] S. D. Li and L. Huang, "Pharmacokinetics and biodistribution of nanoparticles," Molecular Pharmaceutics, vol. 5, no. 4, pp. 496-504, 2008.

[35] S. D. Li, S. Chono, and L. Huang, "Efficient oncogene silencing and metastasis inhibition via systemic delivery of siRNA," Molecular Therapy, vol. 16, no. 5, pp. 942-946, 2008.

[36] J. W. Holland, C. Hui, P. R. Cullis, and T. D. Madden, "Poly(ethylene glycol)-lipid conjugates regulate the calcium-induced fusion of liposomes composed of phosphatidylethanolamine and phosphatidylserine," Biochemistry, vol. 35, no. 8, pp. 2618-2624, 1996.

[37] J. J. Wheeler, L. Palmer, M. Ossanlou et al., "Stabilized plasmid-lipid particles: construction and characterization," Gene Therapy, vol. 6, no. 2, pp. 271-281, 1999.

[38] M. A. Monck, A. Mori, D. Lee et al., "Stabilized plasmid-lipid particles: pharmacokinetics and plasmid delivery to distal tumors following intravenous injection," Journal of Drug Targeting, vol. 7, no. 6, pp. 439-452, 2000.
[39] O. Ishida, K. Maruyama, H. Tanahashi et al., "Liposomes bearing polyethyleneglycol-coupled transferrin with intracellular targeting property to the solid tumors in vivo," Pharmaceutical Research, vol. 18, no. 7, pp. 1042-1048, 2001.

[40] M. Ogris, G. Walker, T. Blessing, R. Kircheis, M. Wolschek, and E. Wagner, "Tumor-targeted gene therapy: strategies for the preparation of ligand-polyethylene glycol-polyethylenimine/DNA complexes," Journal of Controlled Release, vol. 91, no. 1-2, pp. 173-181, 2003.

[41] M. E. Davis, "The first targeted delivery of siRNA in humans via a self-assembling, cyclodextrin polymer-based nanoparticle: from concept to clinic," Molecular Pharmaceutics, vol. 6, no. 3, pp. 659-668, 2009.

[42] M. E. Davis, J. E. Zuckerman, C. H. J. Choi et al., "Evidence of RNAi in humans from systemically administered siRNA via targeted nanoparticles," Nature, vol. 464, no. 7291, pp. 10671070,2010

[43] N. C. Bellocq, S. H. Pun, G. S. Jensen, and M. E. Davis, "Transferrin-containing, cyclodextrin polymer-based particles for tumor-targeted gene delivery," Bioconjugate Chemistry, vol. 14, no. 6, pp. 1122-1132, 2003.

[44] R. M. Schiffelers, A. Ansari, J. Xu et al., "Cancer siRNA therapy by tumor selective delivery with ligand-targeted sterically stabilized nanoparticle," Nucleic Acids Research, vol. 32, no. 19, p. e149, 2004.

[45] H. D. Han, L. S. Mangala, J. W. Lee et al., "Targeted gene silencing using RGD-labeled chitosan nanoparticles," Clinical Cancer Research, vol. 16, no. 15, pp. 3910-3922, 2010.

[46] S. Moffatt, S. Wiehle, and R. J. Cristiano, "A multifunctional PEI-based cationic polyplex for enhanced systemic p53-mediated gene therapy," Gene Therapy, vol. 13, no. 21, pp. 15121523, 2006.

[47] S. Chono, S. D. Li, C. C. Conwell, and L. Huang, "An efficient and low immunostimulatory nanoparticle formulation for systemic siRNA delivery to the tumor," Journal of Controlled Release, vol. 131, no. 1, pp. 64-69, 2008.

[48] S. H. Kim, J. H. Jeong, K. C. Cho, S. W. Kim, and T. G. Park, "Target-specific gene silencing by siRNA plasmid DNA complexed with folate-modified poly(ethylenimine)," Journal of Controlled Release, vol. 104, no. 1, pp. 223-232, 2005.

[49] S. Guo, Y. Huang, W. Zhang et al., "Ternary complexes of amphiphilic polycaprolactone-graft-poly (N,Ndimethylaminoethyl methacrylate), DNA and polyglutamic acid-graft-poly(ethylene glycol) for gene delivery," Biomaterials, vol. 32, no. 18, pp. 4283-4292, 2011.

[50] W. Li, Z. Huang, J. A. MacKay, S. Grube, and F. C. Szoka, "Low-pH-sensitive poly(ethylene glycol) (PEG)-stabilized plasmid nanolipoparticles: effects of PEG chain length, lipid composition and assembly conditions on gene delivery," Journal of Gene Medicine, vol. 7, no. 1, pp. 67-79, 2005.

[51] C. Masson, M. Garinot, N. Mignet et al., "pH-Sensitive PEG lipids containing orthoester linkers: new potential tools for nonviral gene delivery," Journal of Controlled Release, vol. 99, no. 3, pp. 423-434, 2004.

[52] G. F. Walker, C. Fella, J. Pelisek et al., "Toward synthetic viruses: endosomal $\mathrm{pH}$-Triggered deshielding of targeted polyplexes greatly enhances gene transfer in vitro and in vivo," Molecular Therapy, vol. 11, no. 3, pp. 418-425, 2005.

[53] R. M. Sawant, J. P. Hurley, S. Salmaso et al., "“SMART” drug delivery systems: double-targeted $\mathrm{pH}$-responsive pharmaceutical nanocarriers," Bioconjugate Chemistry, vol. 17, no. 4, pp. 943-949, 2006.

[54] J. Shin, P. Shum, and D. H. Thompson, "Acid-triggered release via dePEGylation of DOPE liposomes containing 
acid-labile vinyl ether PEG-lipids," Journal of Controlled Release, vol. 91, no. 1-2, pp. 187-200, 2003.

[55] N. Murthy, J. Campbell, N. Fausto, A. S. Hoffman, and P. S. Stayton, "Design and synthesis of $\mathrm{pH}$-responsive polymeric carriers that target uptake and enhance the intracellular delivery of oligonucleotides," Journal of Controlled Release, vol. 89, no. 3, pp. 365-374, 2003.

[56] B. Romberg, W. E. Hennink, and G. Storm, "Sheddable coatings for long-circulating nanoparticles," Pharmaceutical Research, vol. 25, no. 1, pp. 55-71, 2008.

[57] H. Hatakeyama, H. Akita, K. Kogure et al., "Development of a novel systemic gene delivery system for cancer therapy with a tumor-specific cleavable PEG-lipid," Gene Therapy, vol. 14, no. 1, pp. 68-77, 2007.

[58] L. M. Coussens, B. Fingleton, and L. M. Matrisian, "Matrix metalloproteinase inhibitors and cancer: trials and tribulations," Science, vol. 295, no. 5564, pp. 2387-2392, 2002.

[59] E. T. M. Dams, P. Laverman, W. J. G. Oyen et al., "Accelerated blood clearance and altered biodistribution of repeated injections of sterically stabilized liposomes," Journal of Pharmacology and Experimental Therapeutics, vol. 292, no. 3, pp. 1071-1079, 2000.

[60] T. Ishida and H. Kiwada, "Accelerated blood clearance $(\mathrm{ABC})$ phenomenon upon repeated injection of PEGylated liposomes," International Journal of Pharmaceutics, vol. 354, no. 1-2, pp. 56-62, 2008.

[61] T. Ishida, R. Maeda, M. Ichihara, K. Irimura, and H. Kiwada, "Accelerated clearance of PEGylated liposomes in rats after repeated injections," Journal of Controlled Release, vol. 88, no. 1, pp. 35-42, 2003.

[62] T. Ishida, M. Ichihara, X. Wang, and H. Kiwada, "Spleen plays an important role in the induction of accelerated blood clearance of PEGylated liposomes," Journal of Controlled Release, vol. 115, no. 3, pp. 243-250, 2006.

[63] T. Ishida, M. Ichihara, X. Wang et al., "Injection of PEGylated liposomes in rats elicits PEG-specific IgM, which is responsible for rapid elimination of a second dose of PEGylated liposomes," Journal of Controlled Release, vol. 112, no. 1, pp. 15-25, 2006.

[64] X. Wang, T. Ishida, and H. Kiwada, "Anti-PEG IgM elicited by injection of liposomes is involved in the enhanced blood clearance of a subsequent dose of PEGylated liposomes," Journal of Controlled Release, vol. 119, no. 2, pp. 236-244, 2007.

[65] T. Ishihara, T. Maeda, H. Sakamoto et al., "Evasion of the accelerated blood clearance phenomenon by coating of nanoparticles with various hydrophilic polymers," Biomacromolecules, vol. 11, no. 10, pp. 2700-2706, 2010.

[66] B. Romberg, C. Oussoren, C. J. Snel, M. G. Carstens, W. E. Hennink, and G. Storm, "Pharmacokinetics of poly(hydroxyethyl-l-asparagine)-coated liposomes is superior over that of PEG-coated liposomes at low lipid dose and upon repeated administration," Biochimica et Biophysica Acta, vol. 1768, no. 3, pp. 737-743, 2007.

[67] H. Xu, K. Q. Wang, Y. H. Deng, and D. W. Chen, "Effects of cleavable PEG-cholesterol derivatives on the accelerated blood clearance of PEGylated liposomes," Biomaterials, vol. 31, no. 17, pp. 4757-4763, 2010.

[68] T. Tagami, K. Nakamura, T. Shimizu, T. Ishida, and H. Kiwada, "Effect of siRNA in PEG-coated siRNA-lipoplex on anti-PEG IgM production," Journal of Controlled Release, vol. 137, no. 3, pp. 234-240, 2009.

[69] N. Yagi, I. Manabe, T. Tottori et al., "A nanoparticle system specifically designed to deliver short interfering RNA inhibits tumor growth in vivo," Cancer Research, vol. 69, no. 16, pp. 6531-6538, 2009.

[70] T. Tagami, Y. Uehara, N. Moriyoshi, T. Ishida, and H. Kiwada, "Anti-PEG IgM production by siRNA encapsulated in a PEGylated lipid nanocarrier is dependent on the sequence of the siRNA," Journal of Controlled Release, vol. 151, no. 2, pp. 149-154, 2011.

[71] O. Boussif, F. LezoualC'H, M. A. Zanta et al., "A versatile vector for gene and oligonucleotide transfer into cells in culture and in vivo: polyethylenimine," Proceedings of the National Academy of Sciences of the United States of America, vol. 92, no. 16, pp. 7297-7301, 1995.

[72] D. Fischer, T. Bieber, Y. Li, H. P. Elsässer, and T. Kissel, "A novel non-viral vector for DNA delivery based on low molecular weight, branched polyethylenimine: effect of molecular weight on transfection efficiency and cytotoxicity," Pharmaceutical Research, vol. 16, no. 8, pp. 1273-1279, 1999.

[73] B. Urban-Klein, S. Werth, S. Abuharbeid, F. Czubayko, and A. Aigner, "RNAi-mediated gene-targeting through systemic application of polyethylenimine (PEI)-complexed siRNA in vivo," Gene Therapy, vol. 12, no. 5, pp. 461-466, 2005.

[74] C. Lin, C. J. Blaauboer, M. M. Timoneda et al., "Bioreducible poly(amido amine)s with oligoamine side chains: synthesis, characterization, and structural effects on gene delivery," Journal of Controlled Release, vol. 126, no. 2, pp. 166-174, 2008.

[75] S. Guo, Y. Huang, Q. Jiang et al., "Enhanced gene delivery and siRNA silencing by gold nanoparticles coated with chargereversal polyelectrolyte," ACS Nano, vol. 4, no. 9, pp. 55055511, 2010.

[76] D. B. Rozema, K. Ekena, D. L. Lewis, A. G. Loomis, and J. A. Wolff, "Endosomolysis by masking of a membrane-active agent (EMMA) for cytoplasmic release of macromolecules," Bioconjugate Chemistry, vol. 14, no. 1, pp. 51-57, 2003.

[77] P. Xu, E. A. van Kirk, Y. H. Zhan, W. J. Murdoch, M. Radosz, and Y. Q. Shen, "Targeted charge-reversal nanoparticles for nuclear drug delivery," Angewandte Chemie, vol. 46, no. 26, pp. 4999-5002, 2007.

[78] Y. Lee, K. Miyata, M. Oba et al., "Charge-conversion ternary polyplex with endosome disruption moiety: a technique for efficient and safe gene delivery," Angewandte Chemie, vol. 47, no. 28, pp. 5163-5166, 2008.

[79] F. Pittella, M. Zhang, Y. Lee et al., "Enhanced endosomal escape of siRNA-incorporating hybrid nanoparticles from calcium phosphate and PEG-block charge-conversional polymer for efficient gene knockdown with negligible cytotoxicity," Biomaterials, vol. 32, no. 11, pp. 3106-3114, 2011.

[80] C. Kusonwiriyawong, P. van de Wetering, J. A. Hubbell, H. P. Merkle, and E. Walter, "Evaluation of pH-dependent membrane-disruptive properties of poly(acrylic acid) derived polymers," European Journal of Pharmaceutics and Biopharmaceutics, vol. 56, no. 2, pp. 237-246, 2003.

[81] T. R. Kyriakides, C. Y. Cheung, N. Murthy, P. Bornstein, P. S. Stayton, and A. S. Hoffman, "pH-sensitive polymers that enhance intracellular drug delivery in vivo," Journal of Controlled Release, vol. 78, no. 1-3, pp. 295-303, 2002.

[82] J. L. Thomas and D. A. Tirrell, "Polyelectrolyte-sensitized phospholipid vesicles," Accounts of Chemical Research, vol. 25, no. 8, pp. 336-342, 1992.

[83] N. Murthy, J. R. Robichaud, D. A. Tirrell, P. S. Stayton, and A. S. Hoffman, "The design and synthesis of polymers for eukaryotic membrane disruption," Journal of Controlled Release, vol. 61, no. 1-2, pp. 137-143, 1999.

[84] R. A. Jones, C. Y. Cheung, F. E. Black et al., "Poly(2-alkylacrylic acid) polymers deliver molecules to the cytosol by 
pH-sensitive disruption of endosomal vesicles," Biochemical Journal, vol. 372, no. 1, pp. 65-75, 2003.

[85] C. Y. Cheung, N. Murthy, P. S. Stayton, and A. S. Hoffman, "A $\mathrm{pH}$-sensitive polymer that enhances cationic lipid-mediated gene transfer," Bioconjugate Chemistry, vol. 12, no. 6, pp. 906910, 2001.

[86] A. J. Convertine, D. S. W. Benoit, C. L. Duvall, A. S. Hoffman, and P. S. Stayton, "Development of a novel endosomolytic diblock copolymer for siRNA delivery," Journal of Controlled Release, vol. 133, no. 3, pp. 221-229, 2009.

[87] A. J. Convertine, C. Diab, M. Prieve et al., "pH-responsive polymeric micelle carriers for siRNA drugs," Biomacromolecules, vol. 11, no. 11, pp. 2904-2911, 2010.

[88] W. J. Kim, L. V. Christensen, S. Jo et al., "Cholesteryl oligoarginine delivering vascular endothelial growth factor siRNA effectively inhibits tumor growth in colon adenocarcinoma," Molecular Therapy, vol. 14, no. 3, pp. 343-350, 2006.

[89] W. J. Kim, C. W. Chang, M. Lee, and S. W. Kim, "Efficient siRNA delivery using water soluble lipopolymer for antiangiogenic gene therapy," Journal of Controlled Release, vol. 118, no. 3, pp. 357-363, 2007.

[90] A. Alshamsan, A. Haddadi, V. Incani, J. Samuel, A. Lavasanifar, and H. Uludağ, "Formulation and delivery of siRNA by oleic acid and stearic acid modified polyethylenimine," Molecular Pharmaceutics, vol. 6, no. 1, pp. 121-133, 2009.

[91] A. Philipp, X. Zhao, P. Tarcha, E. Wagner, and A. Zintchenko, "Hydrophobically modified oligoethylenimines as highly efficient transfection agents for siRNA delivery," Bioconjugate Chemistry, vol. 20, no. 11, pp. 2055-2061, 2009.

[92] G. Creusat and G. Zuber, "Self-assembling polyethylenimine derivatives mediate efficient siRNA delivery in mammalian cells," ChemBioChem, vol. 9, no. 17, pp. 2787-2789, 2008.

[93] J. Chen, H. Tian, Z. Guo et al., "A highly efficient siRNA carrier of PBLG modified hyperbranched PEI," Macromolecular Bioscience, vol. 9, no. 12, pp. 1247-1253, 2009.

[94] H. J. Kim, A. Ishii, K. Miyata et al., "Introduction of stearoyl moieties into a biocompatible cationic polyaspartamide derivative, PAsp(DET), with endosomal escaping function for enhanced siRNA-mediated gene knockdown," Journal of Controlled Release, vol. 145, no. 2, pp. 141-148, 2010.

[95] X. B. Xiong, H. Uludağ, and A. Lavasanifar, "Biodegradable amphiphilic poly(ethylene oxide)-block-polyesters with grafted polyamines as supramolecular nanocarriers for efficient siRNA delivery," Biomaterials, vol. 30, no. 2, pp. 242253, 2009.

[96] C. Q. Mao, J. Z. Du, T. M. Sun et al., “A biodegradable amphiphilic and cationic triblock copolymer for the delivery of siRNA targeting the acid ceramidase gene for cancer therapy," Biomaterials, vol. 32, no. 11, pp. 3124-3133, 2011.

[97] T. M. Sun, J. Z. Du, L. F. Yan, H. Q. Mao, and J. Wang, "Self-assembled biodegradable micellar nanoparticles of amphiphilic and cationic block copolymer for siRNA delivery," Biomaterials, vol. 29, no. 32, pp. 4348-4355, 2008.

[98] C. Zhu, S. Jung, S. Luo et al., "Co-delivery of siRNA and paclitaxel into cancer cells by biodegradable cationic micelles based on PDMAEMA-PCL-PDMAEMA triblock copolymers," Biomaterials, vol. 31, no. 8, pp. 2408-2416, 2010.

[99] Y. Wang, S. Gao, W. H. Ye, H. S. Yoon, and Y. Y. Yang, "Co-delivery of drugs and DNA from cationic core-shell nanoparticles self-assembled from a biodegradable copolymer," Nature Materials, vol. 5, no. 10, pp. 791-796, 2006.

[100] M. S. Shim and Y. J. Kwon, "Acid-transforming polypeptide micelles for targeted nonviral gene delivery," Biomaterials, vol. 31, no. 12, pp. 3404-3413, 2010.
[101] M. S. Shim and Y. J. Kwon, "Controlled delivery of plasmid DNA and siRNA to intracellular targets using ketalized polyethylenimine," Biomacromolecules, vol. 9, no. 2, pp. 444455, 2008.

[102] M. S. Shim, C. S. Kim, Y. C. Ahn, Z. Chen, and Y. J. Kwon, "Combined multimodal optical imaging and targeted gene silencing using stimuli-transforming nanotheragnostics," Journal of the American Chemical Society, vol. 132, no. 24, pp. 8316-8324, 2010.

[103] M. S. Shim and Y. J. Kwon, "Dual mode polyspermine with tunable degradability for plasmid DNA and siRNA delivery," Biomaterials, vol. 32, no. 16, pp. 4009-4020, 2011.

[104] Y. C. Tseng, S. Mozumdar, and L. Huang, "Lipid-based systemic delivery of siRNA," Advanced Drug Delivery Reviews, vol. 61, no. 9, pp. 721-731, 2009.

[105] Y. Xu and F. C. Szoka, "Mechanism of DNA release from cationic liposome/DNA complexes used in cell transfection," Biochemistry, vol. 35, no. 18, pp. 5616-5623, 1996.

[106] A. Schroeder, C. G. Levins, C. Cortez, R. Langer, and D. G. Anderson, "Lipid-based nanotherapeutics for siRNA delivery," Journal of Internal Medicine, vol. 267, no. 1, pp. 921, 2010 .

[107] S. Y. Wu and N. A. J. McMillan, "Lipidic systems for in vivo siRNA delivery," AAPS Journal, vol. 11, no. 4, pp. 639-652, 2009.

[108] Y. Obata, S. Tajima, and S. Takeoka, "Evaluation of pHresponsive liposomes containing amino acid-based zwitterionic lipids for improving intracellular drug delivery in vitro and in vivo," Journal of Controlled Release, vol. 142, no. 2, pp. 267-276, 2010.

[109] J. Li, Y. C. Chen, Y. C. Tseng, S. Mozumdar, and L. Huang, "Biodegradable calcium phosphate nanoparticle with lipid coating for systemic siRNA delivery," Journal of Controlled Release, vol. 142, no. 3, pp. 416-421, 2010.

[110] Y. Chen, S. R. Bathula, J. Li, and L. Huang, "Multifunctional nanoparticles delivering small interfering RNA and doxorubicin overcome drug resistance in cancer," Journal of Biological Chemistry, vol. 285, no. 29, pp. 22639-22650, 2010.

[111] Y. Chen, J. J. Wu, and L. Huang, "Nanoparticles targeted with NGR motif deliver c-myc siRNA and doxorubicin for anticancer therapy," Molecular Therapy, vol. 18, no. 4, pp. 828-834, 2010.

[112] K. Ladewig, M. Niebert, Z. P. Xu, P. P. Gray, and G. Q. M. Lu, "Efficient siRNA delivery to mammalian cells using layered double hydroxide nanoparticles," Biomaterials, vol. 31, no. 7, pp. 1821-1829, 2010.

[113] M. Zhang, A. Lshii, N. Nishiyama et al., "PEGylated calcium phosphate nanocomposites as smart environment-sensitive carriers for siRNA delivery," Advanced Materials, vol. 21, no. 34, pp. 3520-3525, 2009.

[114] Y. Kakizawa, S. Furukawa, and K. Kataoka, "Block copolymer-coated calcium phosphate nanoparticles sensing intracellular environment for oligodeoxynucleotide and siRNA delivery," Journal of Controlled Release, vol. 97, no. 2, pp. 345-356, 2004.

[115] Y. Kakizawa, S. Furukawa, A. Ishii, and K. Kataoka, "Organicinorganic hybrid-nanocarrier of siRNA constructing through the self-assembly of calcium phosphate and PEG-based block aniomer," Journal of Controlled Release, vol. 111, no. 3, pp. 368-370, 2006.

[116] S. Bisht, G. Bhakta, S. Mitra, and A. Maitra, "pDNA load-ed calcium phosphate nanoparticles: highly efficient non-viral vector for gene delivery," International Journal of Pharmaceutics, vol. 288, no. 1, pp. 157-168, 2005. 
[117] S. Hossain, A. Stanislaus, M. J. Chua et al., "Carbonate apatite-facilitated intracellularly delivered siRNA for efficient knockdown of functional genes," Journal of Controlled Release, vol. 147, no. 1, pp. 101-108, 2010.

[118] G. Bhakta, S. Mitra, and A. Maitra, "DNA encapsulated magnesium and manganous phosphate nanoparticles: potential non-viral vectors for gene delivery," Biomaterials, vol. 26, no. 14, pp. 2157-2163, 2005.

[119] G. Bhakta, A. Shrivastava, and A. Maitra, "Magnesium phosphate nanoparticles can be efficiently used in vitro and in vivo as non-viral vectors for targeted gene delivery," Journal of Biomedical Nanotechnology, vol. 5, no. 1, pp. 106-114, 2009.

[120] X. W. He, T. Liu, Y. X. Chen et al., "Calcium carbonate nanoparticle delivering vascular endothelial growth factor- $\mathrm{C}$ siRNA effectively inhibits lymphangiogenesis and growth of gastric cancer in vivo," Cancer Gene Therapy, vol. 15, no. 3, pp. 193-202, 2008.

[121] T. B. Wyman, F. Nicol, O. Zelphati, P. V. Scaria, C. Plank, and F. C. Szoka, "Design, synthesis, and characterization of a cationic peptide that binds to nucleic acids and permeabilizes bilayers," Biochemistry, vol. 36, no. 10, pp. 3008-3017, 1997.

[122] H. Lee, J. H. Jeong, and T. G. Park, "A new gene delivery formulation of polyethylenimine/DNA complexes coated with PEG conjugated fusogenic peptide," Journal of Controlled Release, vol. 76, no. 1-2, pp. 183-192, 2001.

[123] W. Li, F. Nicol, and F. C. Szoka, "GALA: a designed synthetic $\mathrm{pH}$-responsive amphipathic peptide with applications in drug and gene delivery," Advanced Drug Delivery Reviews, vol. 56, no. 7, pp. 967-985, 2004.

[124] H. Hatakeyama, H. Akita, and H. Harashima, "A multifunctional envelope type nano device (MEND) for gene delivery to tumours based on the EPR effect: a strategy for overcoming the PEG dilemma," Advanced Drug Delivery Reviews, vol. 63, no. 3, pp. 152-160, 2011.

[125] H. Hatakeyama, E. Ito, H. Akita et al., "A pH-sensitive fusogenic peptide facilitates endosomal escape and greatly enhances the gene silencing of siRNA-containing nanoparticles in vitro and in vivo," Journal of Controlled Release, vol. 139, no. 2, pp. 127-132, 2009.

[126] Y. Sakurai, H. Hatakeyama, H. Akita et al., "Efficient short interference rna delivery to tumor cells using a combination of octaarginine, gala and tumor-specific, cleavable polyethylene glycol system," Biological and Pharmaceutical Bulletin, vol. 32, no. 5, pp. 928-932, 2009.

[127] N. Ferrer-Miralles, E. Vázquez, and A. Villaverde, "Membrane-active peptides for non-viral gene therapy: making the safest easier," Trends in Biotechnology, vol. 26, no. 5, pp. 267-275, 2008.

[128] P. R. Cullis, M. J. Hope, and C. P. S. Tilcock, "Lipid polymorphism and the roles of lipids in membranes," Chemistry and Physics of Lipids, vol. 40, no. 2-4, pp. 127-144, 1986.

[129] I. M. Hafez, N. Maurer, and P. R. Cullis, "On the mechanism whereby cationic lipids promote intracellular delivery of polynucleic acids," Gene Therapy, vol. 8, no. 15, pp. 11881196, 2001.

[130] J. Heyes, L. Palmer, K. Bremner, and I. MacLachlan, "Cationic lipid saturation influences intracellular delivery of encapsulated nucleic acids," Journal of Controlled Release, vol. 107, no. 2, pp. 276-287, 2005.

[131] S. C. Semple, A. Akinc, J. Chen et al., "Rational design of cationic lipids for siRNA delivery," Nature Biotechnology, vol. 28, no. 2, pp. 172-176, 2010.

[132] H. J. Lim, D. Masin, N. L. Mcintosh, T. D. Madden, and M. B. Bally, "Role of drug release and liposome-mediated drug delivery in governing the therapeutic activity of liposomal mitoxantrone used to treat human A431 and LS180 solid tumors," Journal of Pharmacology and Experimental Therapeutics, vol. 292, no. 1, pp. 337-345, 2000.

[133] L. D. Mayer, L. C. L. Tai, D. S. C. Ko et al., "Influence of vesicle size, lipid composition, and drug-to-lipid ratio on the biological activity of liposomal doxorubicin in mice," Cancer Research, vol. 49, no. 21, pp. 5922-5930, 1989.

[134] N. L. Boman, L. D. Mayer, and P. R. Cullis, "Optimization of the retention properties of vincristine in liposomal systems," Biochimica et Biophysica Acta, vol. 1152, no. 2, pp. 253-258, 1993.

[135] A. Gabizon, M. Chemla, D. Tzemach, A. T. Horowitz, and D. Goren, "Liposome longevity and stability in circulation: effects on the in vivo delivery to tumors and therapeutic efficacy of encapsulated anthracyclines," Journal of Drug Targeting, vol. 3, no. 5, pp. 391-398, 1996.

[136] C. Boyer and J. A. Zasadzinski, "Multiple lipid compartments slow vesicle contents release in lipases and serum," ACS Nano, vol. 1, no. 3, pp. 176-182, 2007.

[137] L. D. Mayer, R. Nayar, R. L. Thies, N. L. Boman, P. R. Cullis, and M. B. Bally, "Identification of vesicle properties that enhance the antitumour activity of liposomal vincristine against murine L1210 leukemia," Cancer Chemotherapy and Pharmacology, vol. 33, no. 1, pp. 17-24, 1993.

[138] B. Chandra, R. Subramaniam, S. Mallik, and D. K. Srivastava, "Formulation of photocleavable liposomes and the mechanism of their content release," Organic and Biomolecular Chemistry, vol. 4, no. 9, pp. 1730-1740, 2006.

[139] A. I. Elegbede, J. Banerjee, A. J. Hanson et al., "Mechanistic studies of the triggered release of liposomal contents by matrix metalloproteinase-9," Journal of the American Chemical Society, vol. 130, no. 32, pp. 10633-10642, 2008.

[140] K. Miyata, M. Oba, M. Nakanishi et al., "Polyplexes from poly(aspartamide) bearing 1,2-diaminoethane side chains induce $\mathrm{pH}$-selective, endosomal membrane destabilization with amplified transfection and negligible cytotoxicity," Journal of the American Chemical Society, vol. 130, no. 48, pp. 16287-16294, 2008.

[141] H. C. Kang, H. J. Kang, and Y. H. Bae, "A reducible polycationic gene vector derived from thiolated low molecular weight branched polyethyleneimine linked by 2 -iminothiolane," Biomaterials, vol. 32, no. 4, pp. 1193-1203, 2011.

[142] X. H. Liu, J. T. Zhang, and D. M. Lynn, "Polyelectrolyte multilayers fabricated from 'charge-shifting' anionic polymers: a new approach to controlled film disruption and the release of cationic agents from surfaces," Soft Matter, vol. 4, no. 8, pp. 1688-1695, 2008.

[143] E. Fattal, S. Nir, R. A. Parente, and F. C. Szoka, "Pore-forming peptides induce rapid phospholipid flip-flop in membranes," Biochemistry, vol. 33, no. 21, pp. 6721-6731, 1994.

[144] A. M. Funhoff, C. F. van Nostrum, M. C. Lok, J. A. W. Kruijtzer, D. J. A. Crommelin, and W. E. Hennink, "Cationic polymethacrylates with covalently linked membrane destabilizing peptides as gene delivery vectors," Journal of Controlled Release, vol. 101, no. 1-3, pp. 233-246, 2005.

[145] N. K. Subbarao, R. A. Parente, F. C. Szoka Jr., L. Nadasdi, and K. Pongracz, "PH-dependent bilayer destabilization by an amphipathic peptide," Biochemistry, vol. 26, no. 11, pp. 2964-2972, 1987.

[146] M. A. Yessine and J. C. Leroux, "Membrane-destabilizing polyanions: interaction with lipid bilayers and endosomal escape of biomacromolecules," Advanced Drug Delivery Reviews, vol. 56, no. 7, pp. 999-1021, 2004. 
[147] M. E. H. El-Sayed, A. S. Hoffman, and P. S. Stayton, "Smart polymeric carriers for enhanced intracellular delivery of therapeutic macromolecules," Expert Opinion on Biological Therapy, vol. 5, no. 1, pp. 23-32, 2005.

[148] D. B. Rozema, K. Ekena, D. L. Lewis, A. G. Loomis, and J. A. Wolff, "Endosomolysis by masking of a membrane-active agent (EMMA) for cytoplasmic release of macromolecules," Bioconjugate Chemistry, vol. 14, no. 1, pp. 51-57, 2003.

[149] M. A. Yessine, M. H. Dufresne, C. Meier, H. U. Petereit, and J. C. Leroux, "Proton-actuated membrane-destabilizing polyion complex micelles," Bioconjugate Chemistry, vol. 18, no. 3, pp. 1010-1014, 2007.

[150] Y. L. Lin, G. Jiang, L. K. Birrell, and M. E. H. El-Sayed, "Degradable, $\mathrm{pH}$-sensitive, membrane-destabilizing, comblike polymers for intracellular delivery of nucleic acids," Biomaterials, vol. 31, no. 27, pp. 7150-7166, 2010.

[151] T. Takahashi, K. Kono, T. Itoh, N. Emi, and T. Takagishi, "Synthesis of novel cationic lipids having polyamidoamine dendrons and their transfection activity," Bioconjugate Chemistry, vol. 14, no. 4, pp. 764-773, 2003.

[152] Z. Yang, G. Sahay, S. Sriadibhatla, and A. V. Kabanov, "Amphiphilic block copolymers enhance cellular uptake and nuclear entry of polyplex-delivered DNA," Bioconjugate Chemistry, vol. 19, no. 10, pp. 1987-1994, 2008.

[153] Z. Liu, Z. Zhang, C. Zhou, and Y. Jiao, "Hydrophobic modifications of cationic polymers for gene delivery," Progress in Polymer Science, vol. 35, no. 9, pp. 1144-1162, 2010.

[154] S. Guo, Y. Huang, T. Wei et al., "Amphiphilic and biodegradable methoxy polyethylene glycol-block-(polycaprolactonegraft-poly(2-(dimethylamino)ethyl methacrylate)) as an effective gene carrier," Biomaterials, vol. 32, no. 3, pp. 879$889,2011$.

[155] A. Dehshahri, R. K. Oskuee, W. T. Shier, A. Hatefi, and M. Ramezani, "Gene transfer efficiency of high primary amine content, hydrophobic, alkyl-oligoamine derivatives of polyethylenimine," Biomaterials, vol. 30 , no. 25, pp. $4187-$ 4194, 2009.

[156] S. Katayama, H. Hirose, K. Takayama, I. Nakase, and S. Futaki, "Acylation of octaarginine: implication to the use of intracellular delivery vectors," Journal of Controlled Release, vol. 149, no. 1, pp. 29-35, 2011.

[157] M. S. Shim and Y. J. Kwon, "Acid-responsive linear polyethylenimine for efficient, specific, and biocompatible siRNA delivery," Bioconjugate Chemistry, vol. 20, no. 3, pp. 488-499, 2009.

[158] M. S. Shim and Y. J. Kwon, "Controlled cytoplasmic and nuclear localization of plasmid DNA and siRNA by differentially tailored polyethylenimine," Journal of Controlled Release, vol. 133, no. 3, pp. 206-213, 2009. 

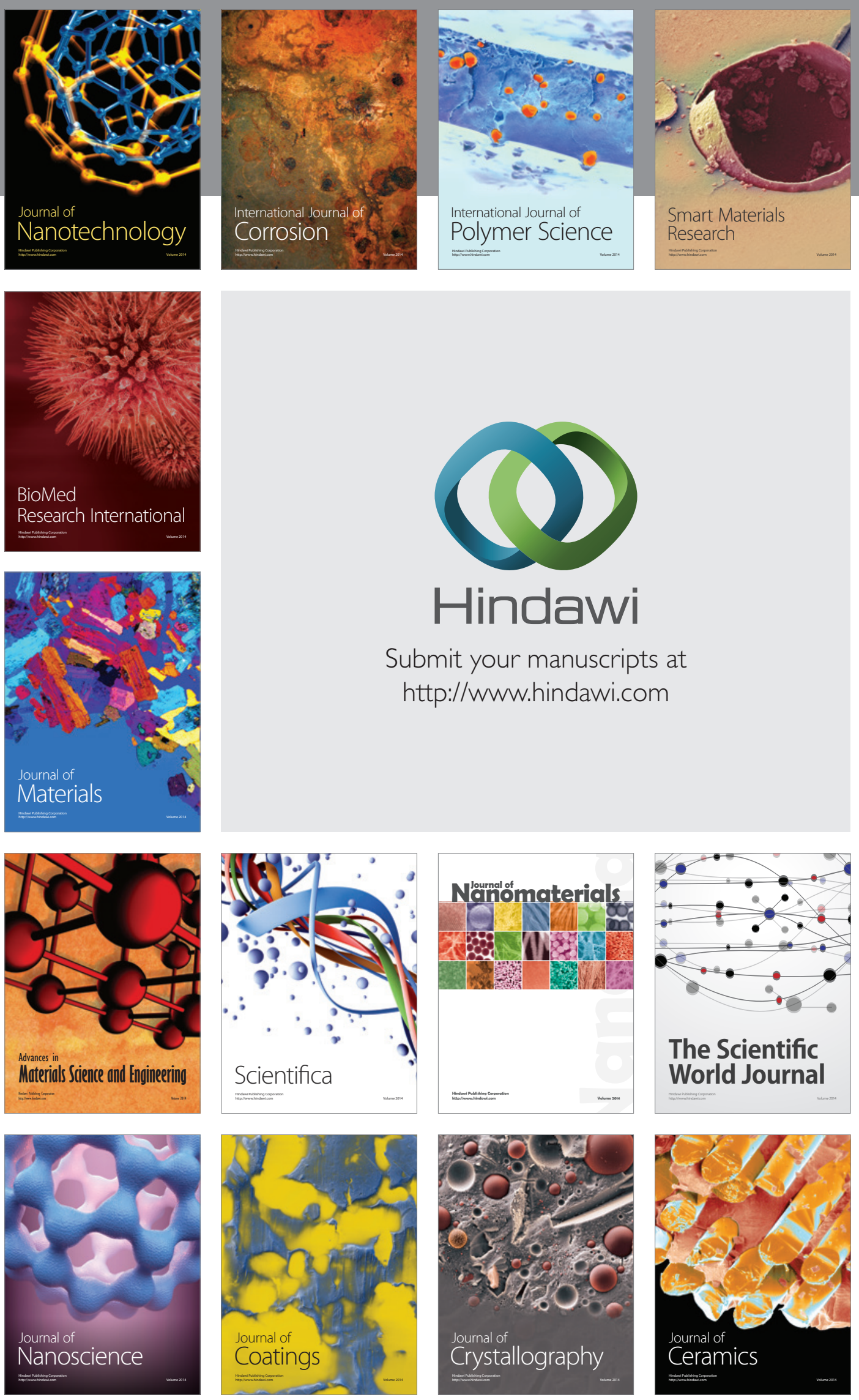

The Scientific World Journal

Submit your manuscripts at

http://www.hindawi.com

\section{World Journal}

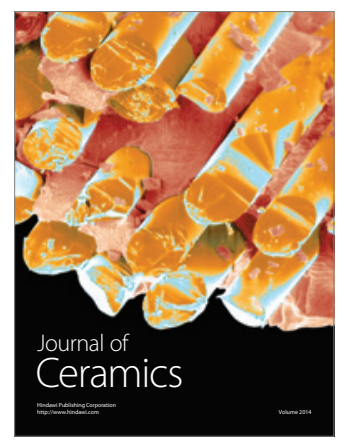

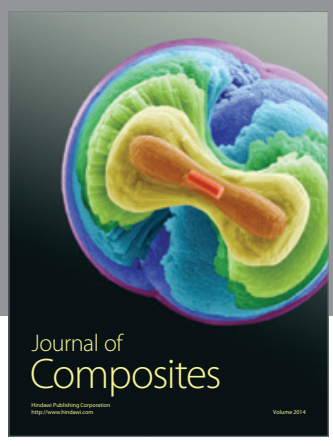
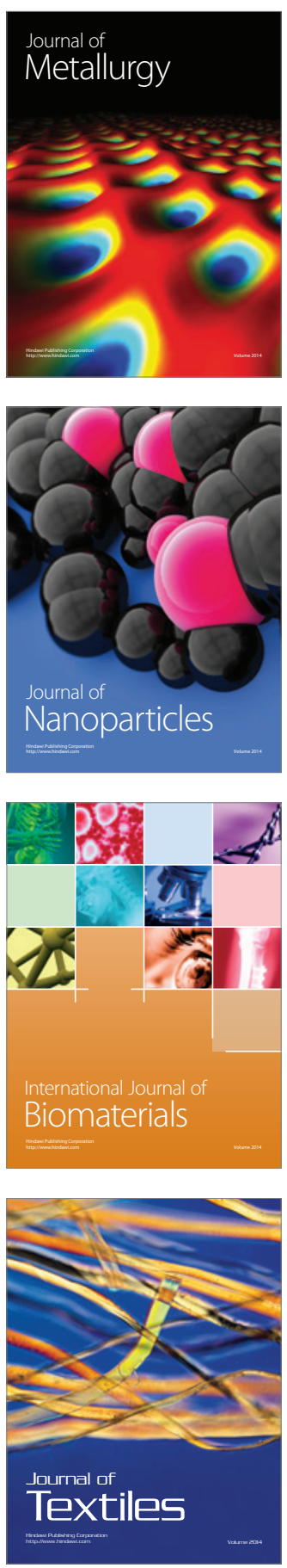